\title{
Evaluation of the Reliability and Validity of a Questionnaire Gauging Students' Satisfaction with Training Chairs
}

\author{
Samira Ansari ${ }^{1}$, Atiye Sadat Ghazi ${ }^{2}$, Sakineh Varmazyar ${ }^{3, *}$ \\ ${ }^{I}$ MSc Student of Occupational Health Engineering, Faculty of Health, Qazvin University of Medical Sciences, Qazvin, Iran \\ ${ }^{2}$ BSc Student of Occupational Health Engineering, Faculty of Health, Qazvin University of Medical Sciences, Qazvin, Iran \\ ${ }^{3}$ Assistant Professor, Department of Occupational Health Engineering, Faculty of Health, Qazvin University of Medical \\ Sciences, Qazvin, Iran \\ * Corresponding Author: Sakineh Varmazyar, Department of Occupational Health Engineering, Faculty of Health, Qazvin \\ University of Medical Sciences, Qazvin, Iran.Email: Svarmazyar@qums.ac.ir
}

\begin{abstract}
Received: $18 / 07 / 2017$

Accepted: 13/08/2017

How to Cite this Article: Ansari S, Ghazi AS, Varmazyar S. Evaluation of the Reliability and Validity of a Questionnaire Gauging Students' Satisfaction with Training Chairs. J Occup Hyg Eng. 2017; 4(2): 1-6. DOI: 10.18869/acadpub.johe.4.2.1

Background and Objective: Given that satisfaction with educational facilities and feeling comfortable in the classroom can affect learning, focus, and productivity, the necessity for a valid and reliable questionnaire that is appropriate for determining students' satisfaction with training chairs has been recognized. Therefore, we aimed to design and validate a training chair satisfaction questionnaire.

Materials and Methods: This descriptive study was performed in two phases, that is, designing and examining the validity and reliability of the satisfaction questionnaire and determining its cut-off point in 2016. To determine the content validity of the questionnaire, content validity ratio (CVR) and content validity index (CVI) were used, and to determine its external and internal reliability, test-retest and Cronbach's alpha methods were adopted. Also, the receiver operating characteristic (ROC) curve was utilized for specifying its sensitivity, specificity, and cut-off point.

Results: CVI was calculated at 0.798, which is acceptable for this questionnaire. Cronbach's alpha coefficient was estimated at 0.799 and the correlation between the questions in first and second series was in an acceptable significance level $(\mathrm{r}=0.825 ; \mathrm{P}=0.000)$. In the $\mathrm{ROC}$, the cut-off point was reported as 35.5 with the sensitivity and specificity of $80.9 \%$ and $46.2 \%$, respectively, and area under the ROC curve at this cut-off point was 0.65 .

Conclusion: Based on our results regarding the validity and reliability indices of the questionnaire developed by the researcher, it was noted that this questionnaire is valid and reliable for the assessment of students' satisfaction with training chairs and can be used to examine all office and student chairs.
\end{abstract}

Keywords: Chair; Reliability; Satisfaction; Validity 
doi: 10.18869 /acadpub.johe.4.2.1

\title{
بررسى روايى و هايايى يرسشنامه سنجش رضايتمندى دانشجويان از صندلىهاى آموزشى
}

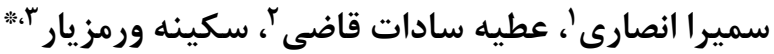

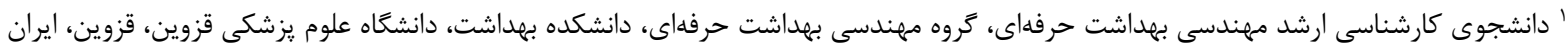

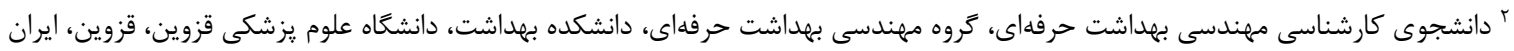

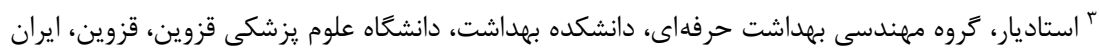

* * نويسنده مسئول: سكينه ورمزيار، كروه مهندسى بهداشت حرفهاى، دانشكده بهداشت، دانشكاه علوم يزشكى قزوين، قزوين، ايران.

ايميل: Svarmazyar@qums.ac.ir

\section{جكيده}

سابقه و هدف: با توجه به اينكه رضايت دانشجويان از تجهيزات آموزشى و احساس راحتى و آرامش آنها در

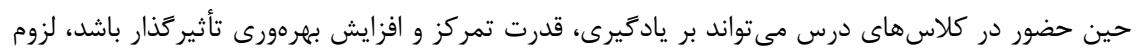

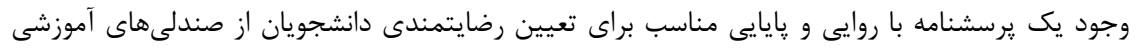

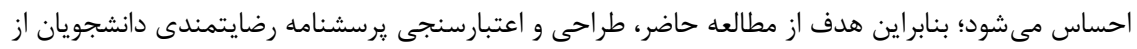
صندلى هاى آموزشى بود.

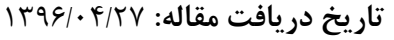

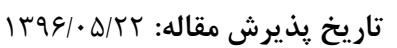
تمامى حقوق نشر براى دانشعاه علوم يزشكى همدان محفوظ است.

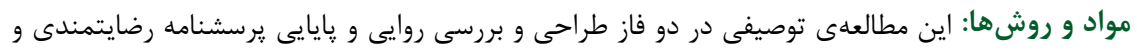

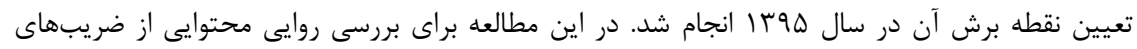
(Content Validity Index) CVI و استفاده شد و با كمك روش رشهاى (Content Validity Ratio) CVR آزمون- بازآزمون و آلفاى كرونباخ، پايايى بيرونى و درونى آن، تعيين گرديد. همجنين براى تعيين حساسيت،

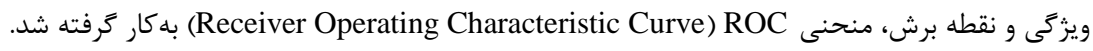

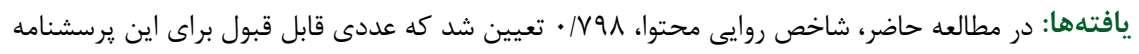

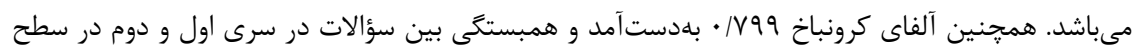

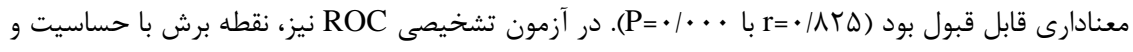

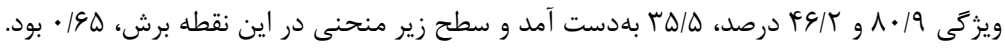

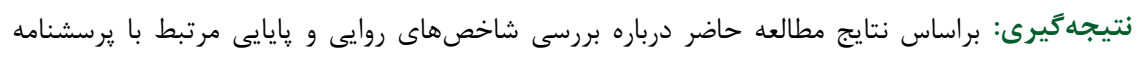

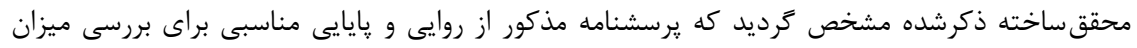

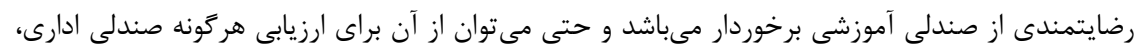
دانش آموزى استفاده نمود.

وازَّان كليدى: بايايى؛ رضايت؛ روايى؛ صندلى

آموزشى فيزيكى با روشهاى مختلف به كيفيت آموزش و يادگيرى

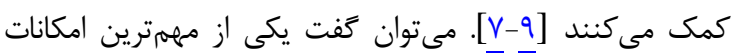

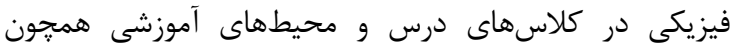

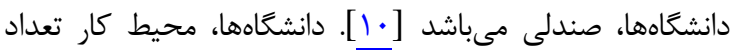

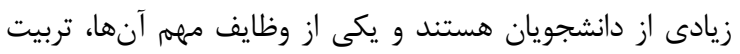

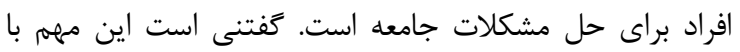
آموزشهاى مؤثر در محيطى ايمن و فاقد استرس، امكانيذير

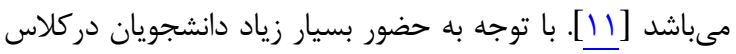

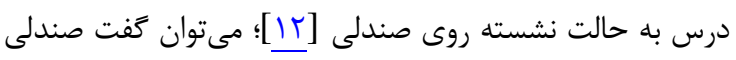

مقدمه محيط زندگى انسان بايد متناسب با وضعيت فيزيكى، روانى

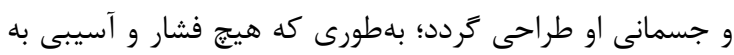
وى وارد نشود. رعايتنكردن تناسب بين محيط خارجى و و وردئ

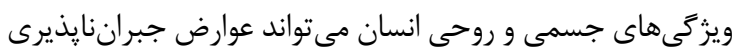

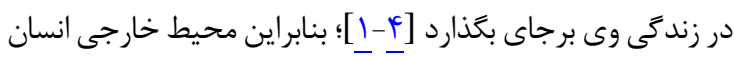

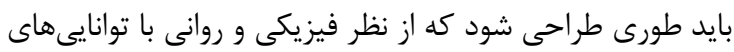

افراد همخوانى داشته باشد [ه] فئ.

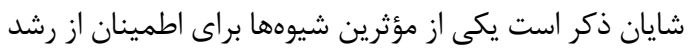

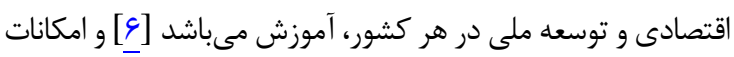


مىتواند بر يادكيرى، قدرت تمركز و افزايش بهرهورى آنها مؤثر

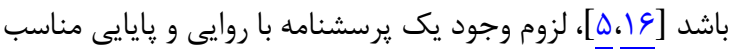

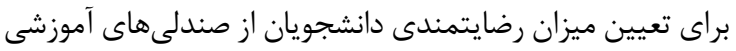

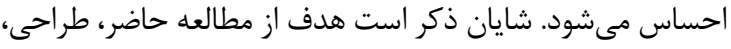

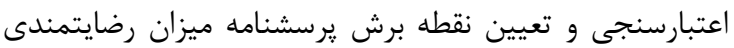
دانشجويان از صندلى هاى آموزشى مىباشد.

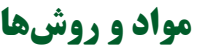

اين مطالعه توصيفى در دو فاز طراحى و بررسى روايى و

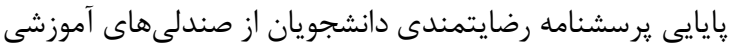

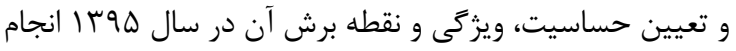

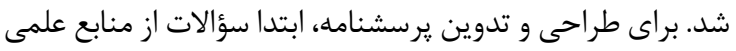

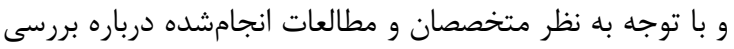

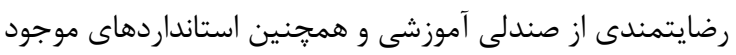

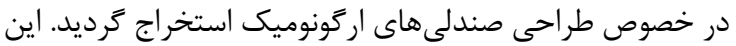

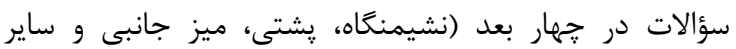

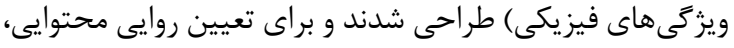

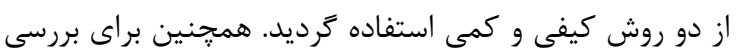
روايى كيفى، سؤالات در اختيار ها ها نفر از متخصصان بهداشت

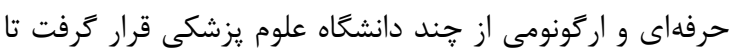

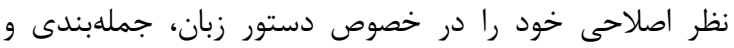

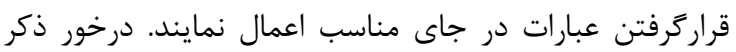

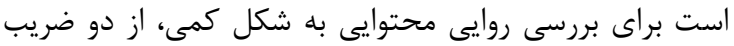

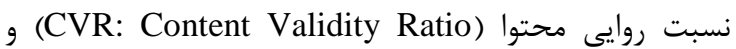
شاخص روايى محتوا (CVI: Content Validity Index) استفاده شد [rr]]. همجنين براى ارزيابى نسبت روايى محتوا، از

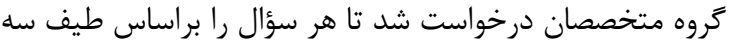

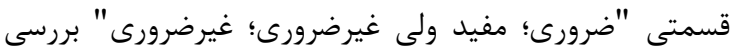

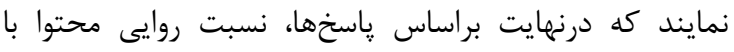

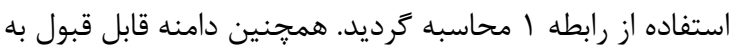
تعداد متخصصان بستكى دارد كه در اين مطالعه براساس قضاوت

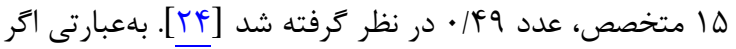

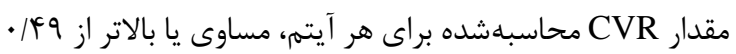

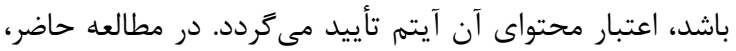

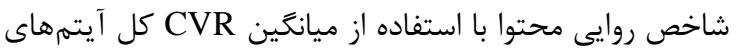

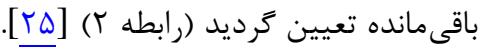

$$
C V R=\frac{n_{E}-\frac{N}{2}}{\frac{N}{2}}
$$

رابطه ne تعداد افراد خبرهاى است كه به گزينه ضرورى ياسخ دادهاند. N N تعداد كل افراد خبره
از وسايلى مىباشد كه نقشى تأثير كذار بر سلامت اين قشر از جامعه

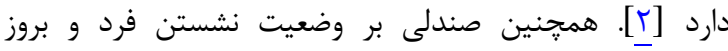

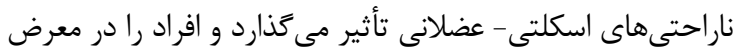

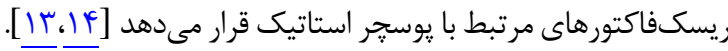

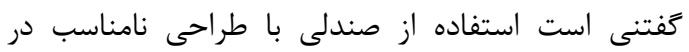

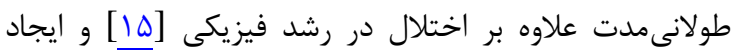

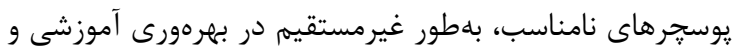

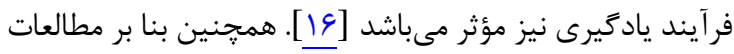

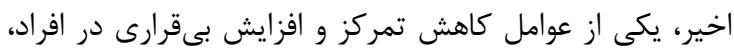

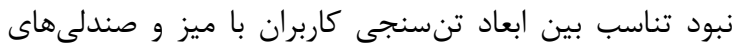

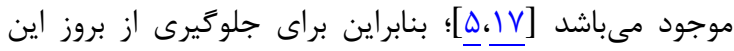

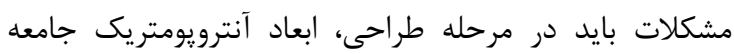

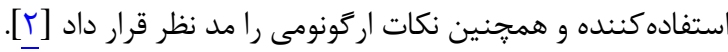

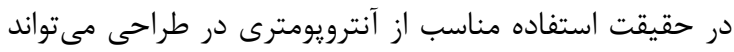

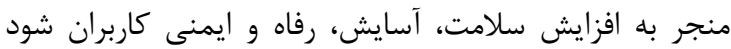
[1/1]. انتظار مىرود صندلى كارآمد بهدليل تأمين راحتى و ايجاد

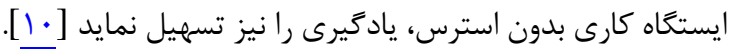

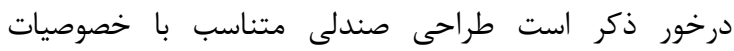
تنسنجى و بر يايه اركونومى سبب مى شود كه فرد هنگًام استفاده

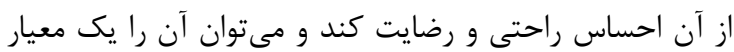

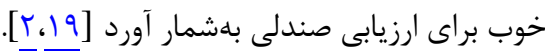

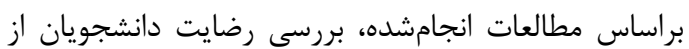

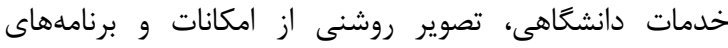

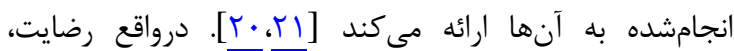

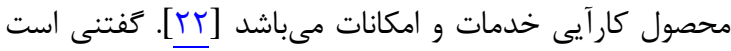

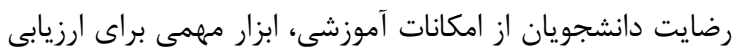

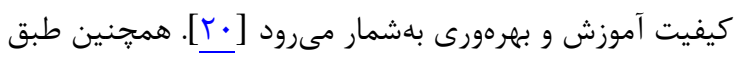

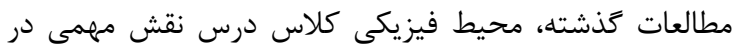

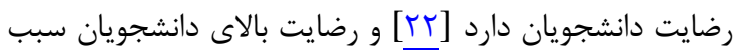

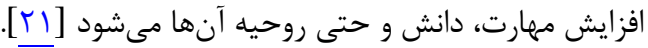

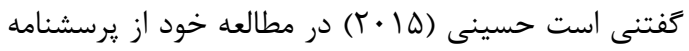

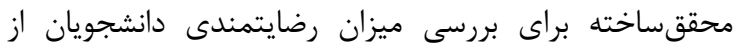

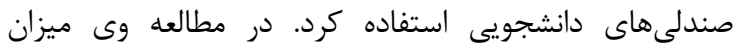

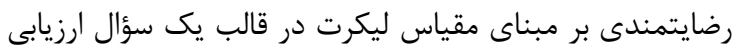

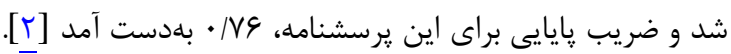

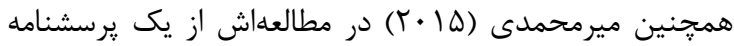

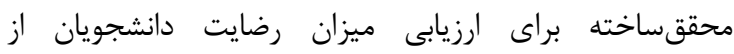

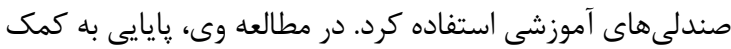

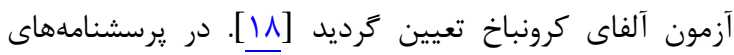

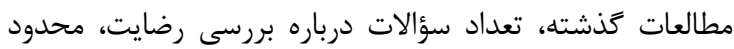

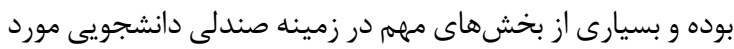

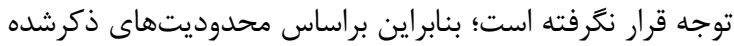

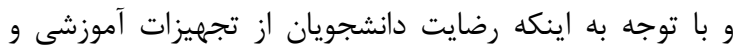

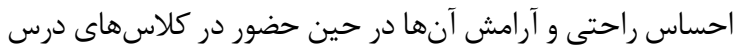


منحنى ابتدا سؤال مرتبط با ارتفاع نشيمنگًاه صندلى بهعنوان

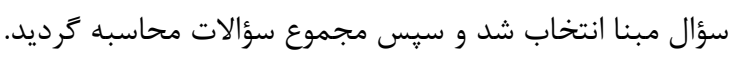
درادامه، سؤال مبنا به طيف ليكرت صفر (كاملاً مخالفم و مخال

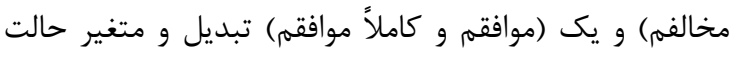
درنظر گرفته شد و مجموع ساير سؤالات به غير از سؤال مبنا نيز

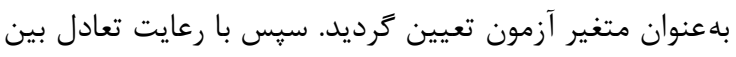

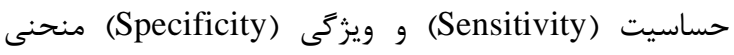
ROC، نقطه برش رضايتمندى از صندلى بلهدست آمد.

\section{كافته}

در مطالعه حاضر، ميانگين و انحراف معيار سن افراد

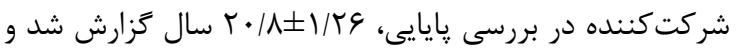
r/r د درصد از شركت كنند

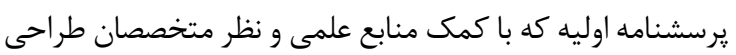

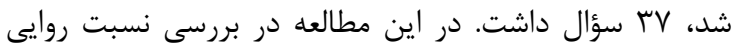

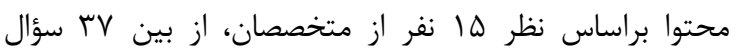

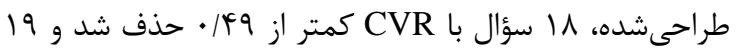
مورد در يرسشنامه باقى ماند كه در جدول ا آورده شد. همجندين

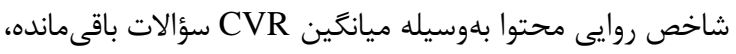

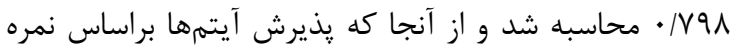

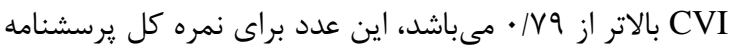

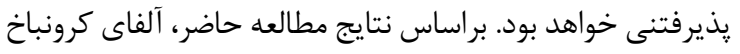

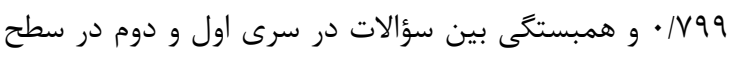

$$
\text { معنادارى قابل قبول بود (Pr }
$$

در اين مطالعه براى تعيين پايايى بيرونى، يرسشنامه توسط

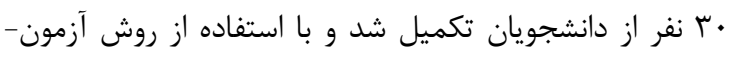

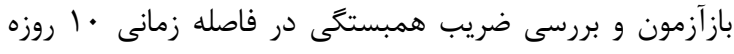

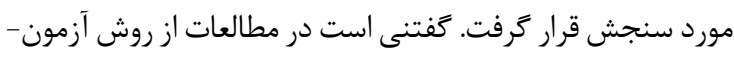

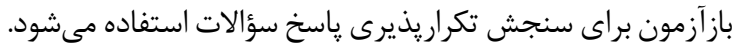

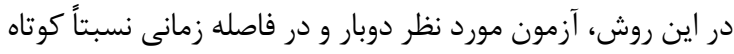

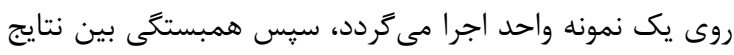

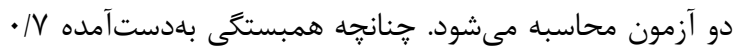

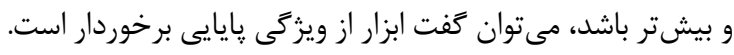

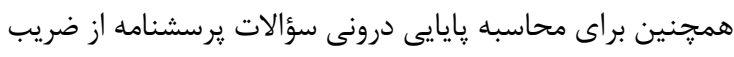

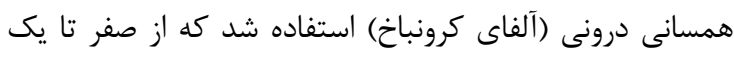

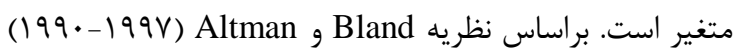

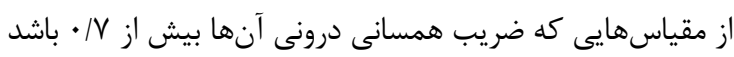

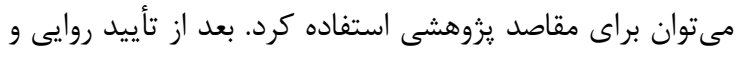

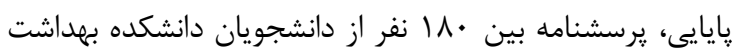

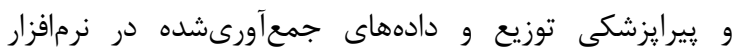
SPSS 20

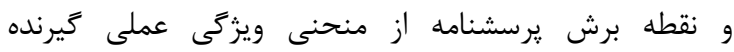
(ROC: Receiver Operating Characteristic Curve) استفاده گرديد. درواقع، منحنى راى نمودارى است كه از تقسيم نسبت حساسيت به مثبت كاذب بلهدست مى آيد. هرجه

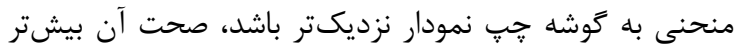

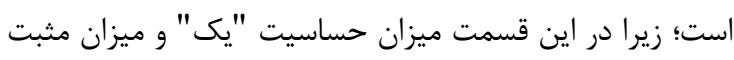

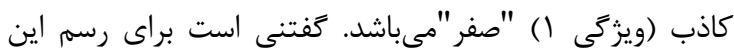

جدول ا: سؤالات باقىمانده در يرسشنامه سنجش ميزان رضايتمندى از صندلىهاى آموزشى

\begin{tabular}{|c|c|c|c|c|c|c|}
\hline كواملاً & 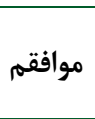 & 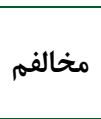 & كاملاً & $\mathrm{CVR} \geq \cdot / 4 q$ & 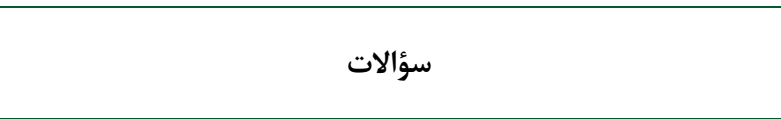 & رديف \\
\hline & & & & $\cdot / A \gamma$ & بله من مى دهد. & 1 \\
\hline & & & & 1 & جنس نشيمنحًاه صندلى به كونهاى است كه از نشستن طولانى مدت روى آن & r \\
\hline & & & & $\cdot / \mathrm{AV}$ & عمق نشيمنكًاه صندلى به من اجازه تكيهدادن به يشتى را مىدهد. & r \\
\hline & & & & $\cdot \mid \mathrm{AV}$ & به هنى ميرد نشستن روى صندلى، كف پاهايم بهطور كامل روى زمين قرار & f \\
\hline & & & & $\cdot / \Lambda V$ & فاصله بين پشت زانو و لبه جلويى صندلى مانع از واردآمدن فشار به پاهايم & $\Delta$ \\
\hline & & & & $\cdot 19$ & مساحت دسته صندلى به اندازه كافى بزرگ است. & \& \\
\hline & & & & $\cdot / 49$ & مىتوانم ارتفاع دسته صندلى را به دلخواه خودم تغيير دهم. & $\checkmark$ \\
\hline & & & & $\cdot / \Lambda \vee$ & ارتفاع دسته صندلى با ارتفاع آرنجم متناسب است. & $\wedge$ \\
\hline & & & & $\cdot / V r$ & فضاى كافى زير دسته صندلى، اجازه حركت به پاهارانهايم را مىدهد. & 9 \\
\hline & & & & $\cdot / \mathrm{rr}$ & فاصله دسته صندلى از بدنم طورى است كه هنكام نوشتن نياز ندارم كردنم را & $1 \cdot$ \\
\hline & & & & $\cdot / \Lambda \vee$ & جنس دسته صندلى طورى است كه مانع فشار به آرنجم مىشود. & 11 \\
\hline & & & & $\cdot / \mathrm{AV}$ & فاصله دسته صندلى طورى است كه هنگام نوشتن، آرنجم در فاصله مناسبى & it \\
\hline
\end{tabular}




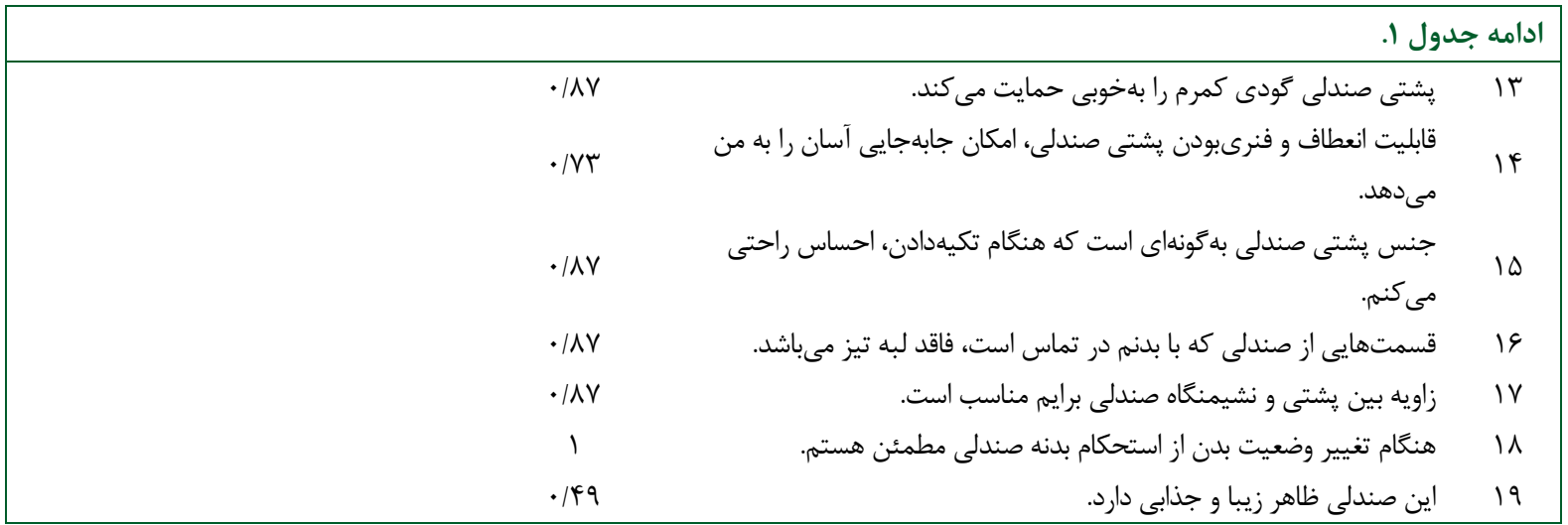

اين متخصصان، تعدادى از سؤالات موجود در يرسشنامه اوليه

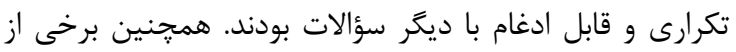

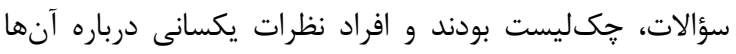

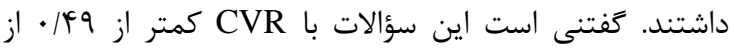

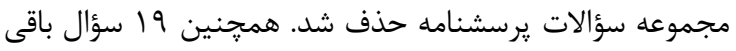

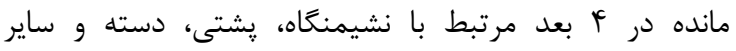
خصوصيات ظاهرى صندلى تقسيمبندى گرديد.

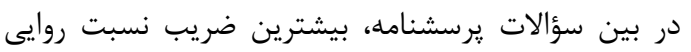

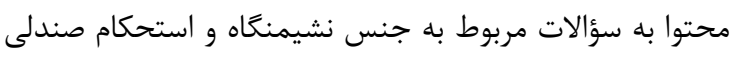

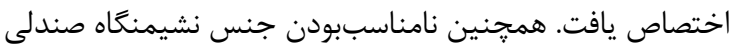

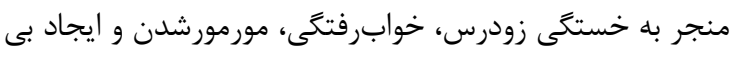

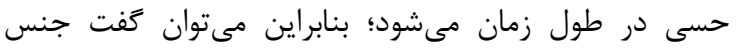

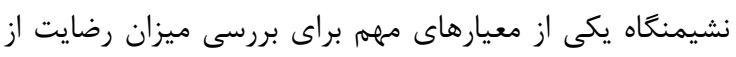

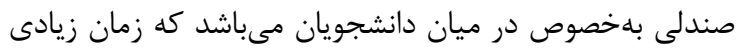

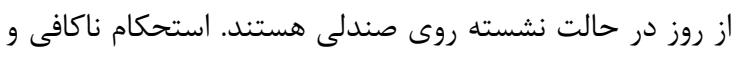

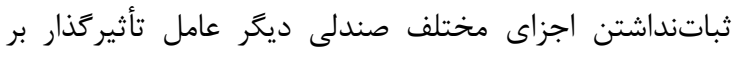

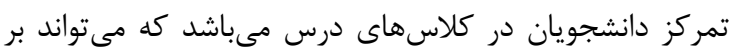
ميزان يادكيرى نيز مؤثر باشد. در مطالعه حاضر شاخص روايى محتوا معروف به نمره كل بلد باشدي

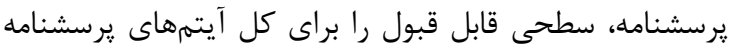

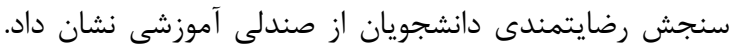

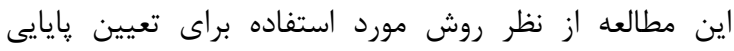

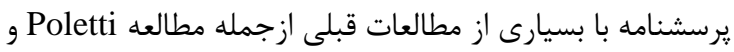

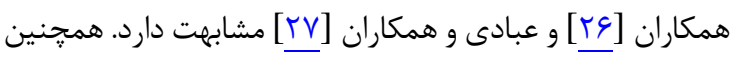

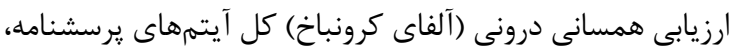

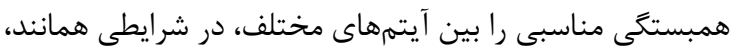

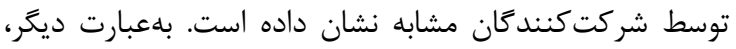

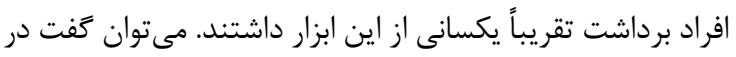
اندازه گيرى اين ابزار خطايى وجود ندارد. در اين مطالعه نتايج همبستخى و همسانى درونى سؤالات با يكديخر كه بيانكر اطمينان آندان

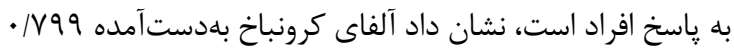

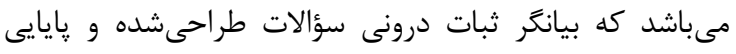

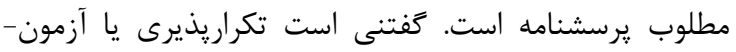

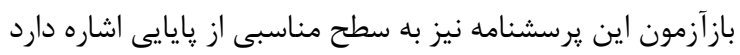

كفتنى است يرسشنامه نهايى داراى يك طيف ليكرت

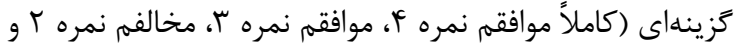

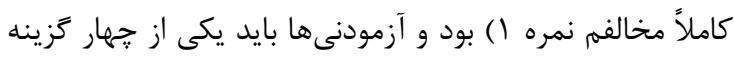

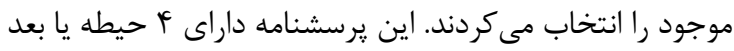

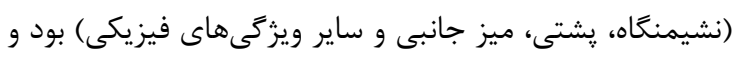
جنس، ابعاد و فواصل هر يك از اين قسمت ها در سؤالات جداكانه مورد سنجش قرار زرفت. منحنى ROC حاصل از رضايتمندى دانشجويان از

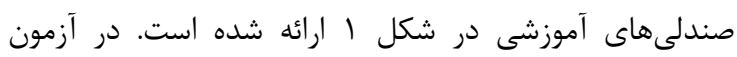
تشخيصى منحنى ROC، نقطه برش با حساسيت و ويزگ

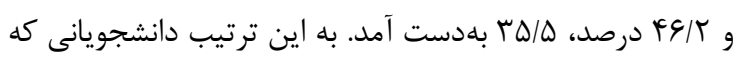

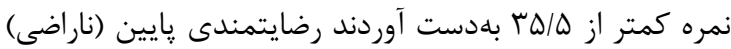

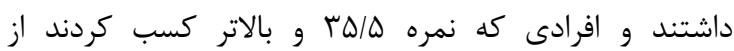
رضايتمندى مطلوبى برخوردار بودند. سطح زير منحنى در اين نقطه برش نيز هاء1 • بود.

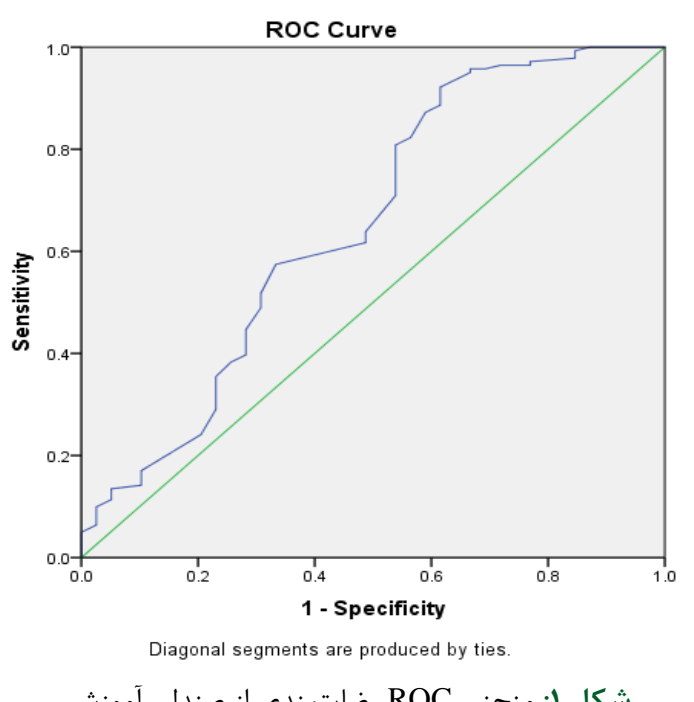
شكل ا: منحنى ROC رضايتمندى از صندلى آموزشى

در مطالعه حاضر، يرسشنامه طراحىشده اوليه، IV سؤال

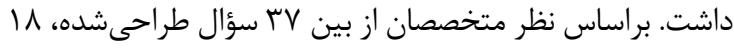

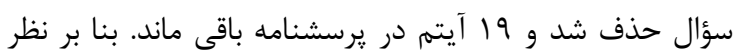




$$
\begin{aligned}
& \text { رضايتمندى از صندلى آموزشى برخوردار مى باشد و حتى مىتوان }
\end{aligned}
$$

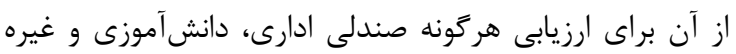

$$
\begin{aligned}
& \text { استفاده نمود. } \\
& \text { در مطالعه حاضر بهدليل همكارىنكردن دانشجويان ساير }
\end{aligned}
$$

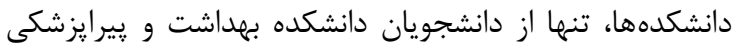

$$
\begin{aligned}
& \text { در تعيين نقطه برش گرسشنامه استفاده كرديد كه ازجمله دئه } \\
& \text { محدوديتهاى اين مطالعه مىباشد. }
\end{aligned}
$$$$
\text { تشكر و قلر داذى }
$$$$
\text { نويسندكان اين مطالعه از دانشجويان دانشكاه علوم يزشكى }
$$$$
\text { قزوين و متخصصان در زمينه بهداشت حرفهاى كه مساعدت لازم }
$$$$
\text { را براى انجام اين مطالعه داشتند، تشكر مى منمايند. }
$$

\section{REFERENCES}

1. Sharifi Z, Osqueizadeh R, Ghomshe ST. Ergonomic design of industrial chair. J Ergon. 2015;3(1):1-9. [Persian]

2. Hosseini MH, Khodadadi M, Hoshiar H, Noorbakhsh AH. The effect of different classroom chairs on the prevalence of musculoskeletal problems and the rate of students' satisfaction. J Health Dev. 2015;4(3):209-18. [Persian]

3. Motamedzade M, Hassan Beigi MR, Mahjoob H. Design and development of an ergonomic chair for Iranian office workers. Zanjan Univ Med Sci J. 2009;17(68):45-52. [Persian]

4. Vink P. Comfort and design: principles and good practice. Florida: CRC Press; 2004.

5. Habibi E, Hoseini M, Asaad Z. Match between school furniture dimensions and children's anthropometry in Isfahan schools. Iran Occup Health. 2009;6(2):51-61. [Persian]

6. Odediran SJ, Gbadegesin JT, Babalola MO. Facilities management practices in the Nigerian public universities. $J$ Facilities Manage. 2015;13(1):5-26. DOI:org/10.1108/JFM11-2013-0058

7. Uline $\mathrm{C}$, Tschannen-Moran $\mathrm{M}$. The walls speak: the interplay of quality facilities, school climate and student achievement. $J$ Educ Admin. 2008;46(1):55-73. DOI:org/10.1108/ 09578230810849817

8. Abdullahi I, Yusoff WZ, Gwamna E. A review of physical and non-physical facilities performance on student satisfaction in Northern Nigerian Universities. Soc Sci. 2017;12(4):600-8.

9. Temple P. Learning spaces in higher education: an underresearched topic. London Rev Educ. 2008;6(3):229-41. DOI: https://doi.org/10.1080/14748460802489363

10. Thariq MM, Munasinghe HP, Abeysekara JD. Designing chairs with mounted desktop for university students: Ergonomics and comfort. Int J Ind Ergon. 2010;40(1):8-18. DOI: https://doi.org/10.1016/j.ergon.2009.10.003

11. Zarei F, Vafaei B, Nikpey A, Varmazyar S, Safari-Variani A. Review the proportion of university seats with body dimensions of students at the School of Public Health of Qazvin University of Medical Sciences in 2009. J Iran Occup Health. 2011;8(3):39-47.

12. Abdoli Eramaki M. Ergonomics. Tehran: Omid Majd Publisher; 1994. P. 275-305.

13. Choobine AR. Principles of educational furniture design. Newsletter Iranian Ergon Soc. 2004;16:3-12.

14. Yees B. Factors that may influence the postural health of schoolchildren (K-12). Work. 1997;9(1):45-55. DOI: 10.3233/WOR-1997-9106

$$
\begin{aligned}
& \text { و بيانگر قابليت تكرار، ثبات و انسجام درونى آيتمهاى ابزار } \\
& \text { مىباشد و در صورت تكرار ابزار اندازهكيرى در شرايط همانند، } \\
& \text { نتايج مشابه حاصل خواهد شد. همجنين همبستخى بين سؤالات } \\
& \text { در سرى اول و دوم يا ضريب پايايى يرسشنامه در اين مطالعه، } \\
& \text { هTM|• بهدست آمد كه اين ميزان بالاتر از ضريب ڤايايى } \\
& \text { يرسشنامه طراحىشده توسط حسينى و همكاران (V9/•) } \\
& \text { مىباشد [r] }
\end{aligned}
$$

\section{نتيجه تيزى}

بنا بر نتايج اين مطالعه، در بررسى شاخصهاى روايى و گايايى

مرتبط با يرسشنامه محققساخته ذكرشده مشخص گرديد كه

اين گيرسشنامه از روايى و گيايايى مناسبى در بررسى ميزان

15. Moon JH, Kang MJ, Kang JK, Kang SW, Kim GH. Evaluation of spinal deformity in Korean female high school student. Ann Rehabil Med. 1995;19(4):846-52.

16. Jung HS. A prototype of an adjustable table and an adjustable chair for schools. Int J Ind Ergon. 2005;35(10):955-69. DOI: https://doi.org/10.1016/j.ergon.2005.04.007

17. Drury CG, Coury BG. A methodology for chair evaluation. $J$ Appl Ergon. 1982;13(3):195-202. DOI: https://doi.org/ 10.1016/0003-6870(82)90006-0

18. Mirmohammadi SJ, Mehrparvar AH, Janaki Alizadeh A. The evaluation of satisfaction of students in hygiene, nursing and paramedical faculties from ergonomic chairs. Quart Occup Med. 2015;7(2):74-84. [Persian]

19. Vafainegad T. Standardization students chair at an elementary school in the city of Sari. Available at: URL: http://wwwpezeshkus/?p=13482; 2012.

20. Hussain S, Jabbar M, Hussain Z, Rehman Z, Saghir A. The students' satisfaction in higher education and its important factors: a comparative study between Punjab and AJ\&K, Pakistan. Res J Appl Sci Eng Tech. 2014;7(20):4343-8.

21. Oluwunmi AO, Ajibola MO, Iroham CO, Eluyele P. Students' satisfaction with major academic facilities in private universities in Ogun State, Nigeria. Covenant J Busin Soc Sci. 2017;8(1):43-59.

22. Hana H, Kiatkawsina K, Kimb W, Hong JH. Physical classroom environment and student satisfaction with courses. Assess Evaluat Higher Educ. 2017;14:1-16. DOI:org/10. 1080/02602938.2017.1299855

23. Hajizadeh A, Asghari M. Methods and statistical analysis looking at the biology and health. $1^{\text {st }}$ ed. Tehran: Publitioning Organ University Jahad; 2011. P. 398-402.

24. DeVon HA, Block ME, Moyle-Wright P, Ernst DM, Hayden SJ, Lazzara DJ, et al. A psychometric toolbox for testing validity and reliability. J Nurs Scholarsh. 2007;39(2):155-64. PMID: 17535316 DOI: 10.1111/j.1547-5069.2007.00161.x

25. Lawshe $\mathrm{CH}$. A quantitative approach to content validity. Person Psychol. 1975;28(4):563-75. DOI: 10.1111/j.17446570.1975.tb01393.x

26. Poletti PL, Piccinelli M, Wilkinson G. Reliability,validity and factor structure of the 12-item General Health Questionnaire among young males in Italey. Acta Psychiatr Scand. 1994;90(6):432-7. PMID: 7892776

27. Ebadi M, Harirchi AM, Shariati M, Garmaroodi GR, Fateh A, Ontazeri A. Translation, reliability and validity of the 12 item general health questionnaire among young people in Iran. Payesh. 2002;1(3):39-46. [Persian] 